\title{
Sequence analysis of VP2 hypervariable region of the field isolates of infectious bursal disease viruses from southern region of India
}

\author{
P. RAJA', T. M. A. SENTHILKUMAR ${ }^{1 *}$, C. V. PRIYADARSHINI ${ }^{1}$, M. PARTHIBAN ${ }^{1}$, A. THANGAVELU ${ }^{2}$, \\ A. MANGALA GOWRI ${ }^{1}$, A. PALANISAMMI ${ }^{1}, \mathrm{~K}_{\text {. KUMANAN }}^{3}$
}

\begin{abstract}
${ }^{1}$ Department of Animal Biotechnology, Madras Veterinary College, Tamilnadu Veterinary and Animal Sciences University, Chennai600007, India; ${ }^{2}$ Department of Veterinary Microbiology, Madras Veterinary College, Tamilnadu Veterinary and Animal Sciences University, Chennai-600007, India; ${ }^{3}$ Dean, Faculty of Basic Sciences, Madras Veterinary College Campus, Tamilnadu Veterinary and Animal Sciences University, Chennai-600007, India
\end{abstract}

\begin{abstract}
Summary. - Infectious bursal disease virus isolates obtained from southern parts of India were subjected to comparative sequencing and phylogenetic analysis of 743bp hypervariable region of VP2. The sequence analysis showed that among eight isolates, only HY12 showed the characteristic conserved amino acid residues at 256I, 294I, and 299S of vvIBDV. Six isolates BGE14, PY12, NKL14, VCN14, RPM14 and EDE14 had conserved amino acid residues at $256 \mathrm{I}$ and $299 \mathrm{~S}$, whereas at residue 294 , isoleucine was substituted by valine. The remaining isolate MB11 had leucine at residue 294 and asparagine at residue 299 similar to classical strain 52/70. The serine-rich heptapeptide sequence SWSASGS adjacent to the second hydrophilic region was conserved in all seven Indian IBDV isolates except isolate MB11. Conservation of this sequence was earlier reported to be an indication of a virus isolate being pathogenic in nature. The reported heptapeptide sequence of the classical strain is 'SWSARGS'. In the present study, 'SWSARGS' heptapeptide sequence was observed in MB11 isolate. The pathogenicity trials conducted with these isolates further confirmed the genome analysis in classification. This study further reveals that the circulating IBDV strains in India could be diverse in nature.
\end{abstract}

Keywords: infectious bursal disease virus; Indian isolates; reverse-transcription polymerase chain reaction; VP2 gene; sequence analysis; amino acid substitutions

\section{Introduction}

Infectious bursal disease (IBD) is caused by an acute, highly contagious nature of birnavirus that results in mortality and immunosuppression of young chickens (Dobos, 1979). Infectious bursal disease virus (IBDV) is a singleshelled, non-enveloped virus that contains a bi-segmented, double-stranded RNA genome (MacDonald, 1980; Muller and Nitschke, 1987). IBDV affects 3-6-week-old chicks, has predilection for bursa of Fabricius and causes prolonged im-

*Corresponding author. E-mail: tmaskumar@yahoo.com, tmaskumar@gmail.com; phone:+919445429353.

Abbreviations: IBD = infectious bursal disease; IBDV = infectious bursal disease virus; cvIBDV = classical virulent IBDV; vvIBDV = very virulent IBDV munosuppression, leading to concurrent viral and bacterial infections along with vaccination failures (Saif, 1991). So far two serotypes of IBDV have been identified; however, only serotype I viruses are naturally pathogenic to chickens (Jackwood et al., 1985). Serotype I strains are classified as classic, variant or very virulent IBDV strains and differ in their virulence, antigenic, and pathogenic properties (Rosenberger $e t$ al., 1985). The IBDV genome is divided into segments A and $\mathrm{B}$, segment $\mathrm{A}$ is about $3.4 \mathrm{~kb}$ and $\mathrm{B}$ is about $2.8 \mathrm{~kb}$. The large segment $\mathrm{A}$ encodes 4 viral proteins, the two capsid proteins, VP2 $(48 \mathrm{kDa})$ and VP3 $(32-35 \mathrm{kDa})$, the viral protease VP4 $(24 \mathrm{kDa})$, and a nonstructural protein VP5 $(17-21 \mathrm{kDa})$, while the smaller segment B encodes VP1 $(90 \mathrm{kDa})$, an RNA-dependent RNA polymerase. Among five proteins of IBDV, the VP2 is the major host-protective antigen that induces serotype-neutralizing antibodies (Fahey et al., 1989), 
the middle third of which contains a highly variable region (HVR) that ranges from amino acid (aa) position 206 to 350 (Bayliss et al., 1990). It includes two hydrophilic regions referred to as VP2 major hydrophilic peak A (aa 212-224) and peak B (aa 314-324) (van den Berg et al., 1991; Schnitzier et al., 1993; Delmas et al., 2005). Mutations within these hydrophilic coding regions are thought to be responsible for the evolution of antigenic variants and virulent serotype 1 strains (Heine et al., 1991; Schnitzier et al., 1993). Three additional minor hydrophilic peaks at aa positions 248-252, 279-290, and 299-305 are considered to influence IBDV antigenicity (van den Berg et al., 1991). At aa position 326-332, there is a serine-rich heptapeptide (SWSASGS), which might have correlation with the virulence of IBDV strains (Heine et al., 1991); this might be one of the virulence markers of IBDV strains. The aa residues at positions 253, 279, and 284 of VP2 are also involved in the virulence (Brandt et al., 2001). VP1 is considered as another important virulence marker of IBDV (Liu and Vakharia, 2004). Most exchanges of amino acid residues in VP2 occur in the four hydrophilic loops of the viral capsid (Coulibaly et al., 2005). These exchanges indicate that the selective pressure for evolution of IBDV is directly focused on the capsid regions that are immediately exposed to the immune system (Durairaj et al., 2011). Amino acid changes that occur within the variable region of VP2 can lead to variations in antibody recognition, antigenicity, immunogenicity, virulence, and tissue tropism of IBDV strains (Fahey et al., 1989; Heine et al., 1991).

\section{Materials and Methods}

Ethics statement. This experiment was approved by the Institutional Animal Ethical Committee of Tamil Nadu Veterinary and Animal Sciences University (Approval Lr. No. 3028/DFBS/B/2014 $\mathrm{dt}, 09.10 .2014)$. All procedures related to the chickens and their care conformed to the internationally accepted principles in the Committee for the Purpose of Controlled Supervision on Experiments on Animals (CPCSEA) Guidelines for Laboratory Animal Facility.

Processing of tissue samples. The bursal tissue samples were collected from various suspected outbreaks during 2011 to 2014 in poultry flocks located in Southern states of India from birds with symptoms of IBDV. The respective observed morbidity and mortality rates ranged from $24-41 \%$ and $3-16 \%$, were confirmed by random samples, which were screened for the presence of IBDV by agar gel immunodiffusion test and reverse transcriptase PCR (RT-PCR) for VP2 gene. Part of the bursal samples were stored in $10 \%$ formalin for histopathological examination and the remaining tissues were minced into fine pieces and suspended in $1 \mathrm{ml}$ of PBS ( $\mathrm{pH}$ 7.4). The suspensions were centrifuged at 2,000 $\mathrm{x} g$ for $30 \mathrm{~min}$ and the supernatants were collected, dispensed into aliquots and stored in $-70^{\circ} \mathrm{C}$ until further processing.
In vitro propagation of IBDV. The positive samples collected from eight different outbreaks of IBD in chickens of 3-5 weeks of age were processed for isolation in cell culture. The samples were inoculated in nine to 10 days old chicken embryos and passaged in primary chick embryo fibroblast (CEF) cultures with antibiotics $(10,000 \mu \mathrm{g} / \mathrm{l}$ streptomycin sulphate and $10,000 \mathrm{IU} / \mathrm{l}$ penicillin $\mathrm{G})$ and antimycotics (Fungizone containing $250 \mu \mathrm{g} / \mathrm{ml}$ Amphotericin $\mathrm{B}$ and $205 \mu \mathrm{g} / \mathrm{ml}$ sodium desoxycholate) (Rodriguez-Chavez et al., 2002). Briefly, CEF monolayers were inoculated with each IBDV isolate directly using the growth medium. The IBDV-infected CEF cells were incubated for 3 to 4 days and the development of cytopathic effect (CPE) was assessed daily. The infected cells were frozen when approximately 50\% CPE was observed. They were subjected to freeze-thawing at $-70^{\circ} \mathrm{C}$ three times and then centrifuged at 2,000 $\mathrm{x} g$ for $10 \mathrm{~min}$. The supernatants containing IBDV were aliquoted and frozen at $-70^{\circ} \mathrm{C}$ until used.

In vivo propagation of IBDV. The bursa-derived IBDV isolates (MB11, HY12, PY12, BGE14, VCN14, NKL14, RPM14 and EDE14) were inoculated in chickens for assessing the virulence of the IBDV strains as described by Rodriguez-Chavez et al. (2002). Eight groups of four-weeks-old native chickens (5 chickens per group) were subjected to the mortality study with these isolates and one group was kept as control. The chickens were inoculated with the virus isolates at a titer of $1 \times 10^{6}$ calculated in terms of $\mathrm{TCID}_{50}$, both by intraocular and intranasal routes. The control group was inoculated with PBS alone. Chickens died up to five days post-inoculation (p.i.) were necropsied and the samples (bursa and spleen) were collected. The average bursal/bodyweight (B/B) and spleen/bodyweight (S/B) ratios were calculated by the following formula (Tanimura et al., 1995):

Bursa weight or spleen weight in grams / Body weight of individual bird in grams x 1000 .

Statistical analysis. The average $\mathrm{B} / \mathrm{B}$ and $\mathrm{S} / \mathrm{B}$ indices between different groups were analyzed statistically by one-way analysis of variance using SPSS version 17.0 software.

Histopathology. Bursa obtained from the inoculated and control groups of chickens were fixed in $10 \%$ buffered formalin solution for at least $48 \mathrm{~h}$ and processed for histopathological examination according to the method described by Tanimura et al. (1995). Briefly, tissues were trimmed to a thickness of $0.5 \mathrm{~cm}$ and the blocks were subsequently dehydrated in series of alcohol, cleared with xylene and embedded in paraffin wax using an automatic tissue processor. The tissues were sectioned at about $5 \mathrm{~mm}$ using a microtome and mounted on glass slides, dewaxed and stained with Hematoxylin and Eosin (H \& E) (Lillie, 1965). A modified lesion scoring method previously established by Muskett et al. (1979) was used to grade the tissues for histopathological changes.

RNA extraction and reverse transcription-PCR. A 20\% (w/v) bursal homogenate was prepared in PBS from both uninfected and infected birds. The supernatants containing bursa-derived IBDV 
strains were aliquoted and stored at $-70^{\circ} \mathrm{C}$ until used. For RNA extraction from the tissue samples, $250 \mu$ of the lysate collected from bursal tissues positive for IBDV (MB11, HY12, PY12, BGE14, VCN14, NKL14, RPM14 and EDE14) were added with $750 \mu \mathrm{l}$ of Trizol reagent (RNA isoplus, Takara) and mixed by pipetting for $10-15$ times. Chloroform, $200 \mu \mathrm{l}$ was added, mixed and the aqueous phase was separated by centrifugation at $15,294 \mathrm{x} g$ for $15 \mathrm{~min}$ at $4^{\circ} \mathrm{C}$. The supernatant was separated and added with $500 \mu \mathrm{l}$ of ice chilled isopropanol, kept for overnight incubation at $-70^{\circ} \mathrm{C}$. The RNA was pelleted by centrifuging at $15,294 \times \mathrm{g}$ for $20 \mathrm{~min}$, the pellet was washed once with $70 \%$ ethanol and air dried. The final pellet was dissolved in $10 \mu \mathrm{l}$ of nuclease free water and stored in $-70^{\circ} \mathrm{C}$ until used.

One-step cDNA synthesis was carried out using cDNA synthesis kit (Thermoscientific, USA) with minor modifications. Briefly, nine $\mu$ l of total RNA extract from each tissue sample was added with $1 \mu \mathrm{l}$ of random hexamer primer, incubated at $65^{\circ} \mathrm{C}$ for $5 \mathrm{~min}$ and immediately chilled on ice. Four $\mu \mathrm{l}$ of reaction buffer, $2 \mu \mathrm{l}$ of 10 mmol dNTP mix, $2 \mu$ of DMSO, $1 \mu$ of Ribolock RNase inhibitor and $1 \mu$ of Revert Aid H Minus M-MuLV reverse transcriptase enzyme were added to the mixture and incubated for five min at $25^{\circ} \mathrm{C}$ followed by $60 \mathrm{~min}$ at $42^{\circ} \mathrm{C}$. The reaction was terminated by heating at $70^{\circ} \mathrm{C}$ for five min, cooled on ice and stored at $-70^{\circ} \mathrm{C}$ until used.

To amplify a 743 bp region of VP2 hypervariable region, the primers 743-FP-(5'-GCCCAGAGTCTACACCAT-3') and 743RP-(5'-CCCGGATTATGTCTTTGA-3') (Jackwood and SommerWagner, 2005) were used. The amplification was carried out in $50 \mu \mathrm{l}$ reaction volume consisting of $25 \mu \mathrm{l}$ of $2 \mathrm{x}$ Mastermix-Red Dye (Ampliqon), two $\mu \mathrm{l}$ of each primer (20 picomoles), $2 \mu \mathrm{l}$ of DMSO, $14 \mu \mathrm{l}$ of nuclease free water and five $\mu \mathrm{l}$ of cDNA from each tissue sample. The amplification was carried out in a thermalcycler (Veriti, Applied Biosystems) with initial denaturation of $94^{\circ} \mathrm{C}$ for $2 \mathrm{~min}$, followed by 30 cycles of $94^{\circ} \mathrm{C}$ for $1.5 \mathrm{~min}, 53^{\circ} \mathrm{C}$ for $1 \mathrm{~min}, 72^{\circ} \mathrm{C}$ for $1 \mathrm{~min}$ and a final extension at $72^{\circ} \mathrm{C}$ for $7 \mathrm{~min}$. Negative control was included in all the PCR reactions. Vaccine strain (Georgia, intermediate strain) was used as positive control (Fig. 1).
Sequence analysis. The PCR amplified products were purified using PCR gel purification kit (Bio Basic Inc, Canada) and sequencing was performed at M/s. Shrimpex Biotech, Chennai-600019 (India). The nucleotide Sequence data was subjected to BLAST analysis (www.ncbi.nlm.nih.gov), assembled and analyzed using Seqman and MegAlign programs of Lasergene package (version 7.1.0) (DNA Star Inc. Madison, WI). Nucleotide sequence alignment was performed by ClustalW method with MegAlign ${ }^{\mathrm{TM}}$ program (DNA Star Inc), and the predicted amino acid sequence was analyzed by Protean ${ }^{\mathrm{TM}}$ program of Lasergene (DNA Star Inc). Phylogenetic analysis of 743 bp sequence containing the hypervariable region of VP2 gene, from nucleotide 881 bp to 1322 bp (numbering system according to Bayliss et al., 1990) was performed using Maximum likelihood method with 1000 bootstrap replication in the MEGA software version 5.

Antigenic index. On the basis of formulations described by Jameson and Wolf (1988), potential antigenic sites of the deduced amino acid sequences were analyzed considering surface probability, regional backbone flexibility, and probable secondary structures of the predicted amino acid sequence using the Protean ${ }^{\mathrm{TM}}$ program (DNA Star Inc. Madison, WI).

\section{Results}

Clinical signs and gross pathological studies on native chickens

The chickens inoculated with isolate MB11 showed mild clinical signs and the mortality was $0 \%$ after 5 days post inoculation, whereas other isolates exhibited typical acute illness of IBDV and mortality from 20 to $40 \%$ after 3 to 4 days post inoculation. In control birds, no abnormalities were recorded throughout the trials. Severe bursal hemorrhages, congestion, paint brush hemorrhages in the muscle of the breast, thigh and legs were observed in chicks inoculated with isolates HY12, PY12, BGE14, VCN14, NKL14, RPM14 and EDE14 except MB11 (Fig. 2).

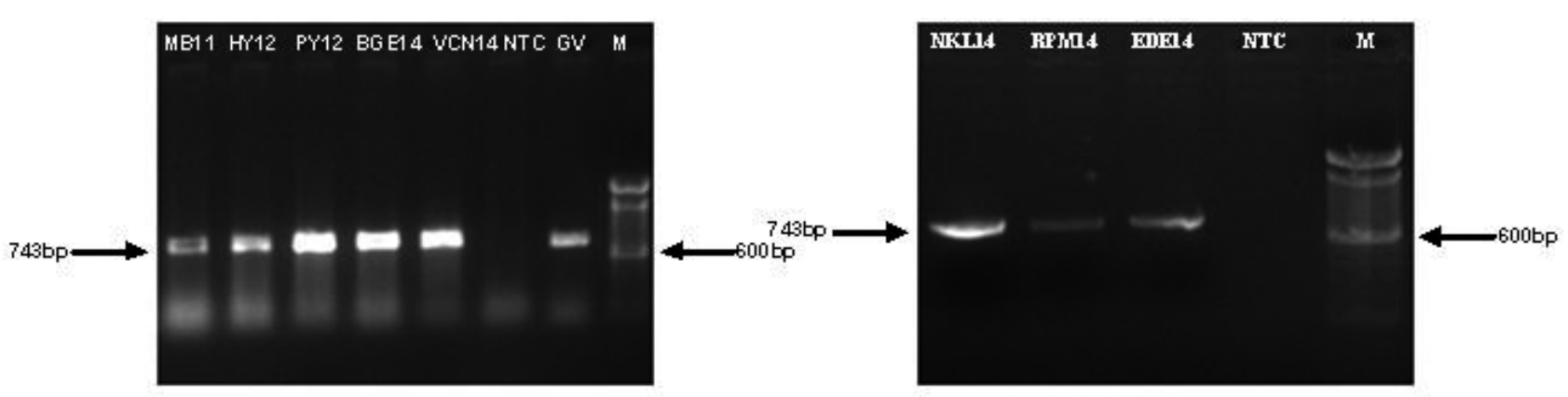

Fig. 1

Amplification of hypervariable region of VP2 gene from the suspected tissues 
(a)

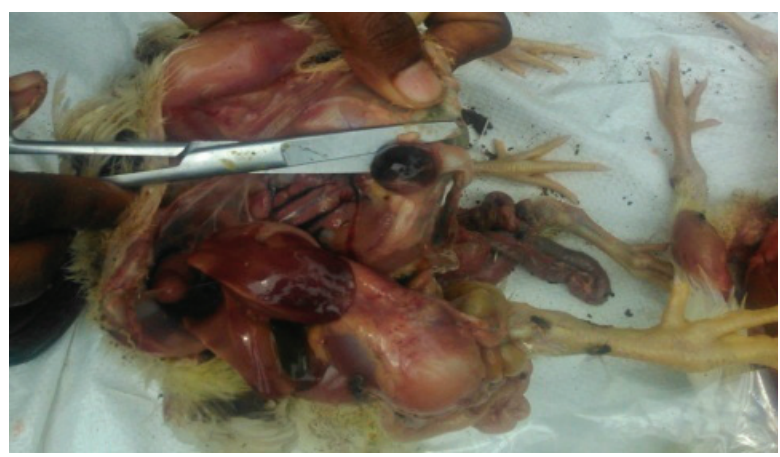

(b)

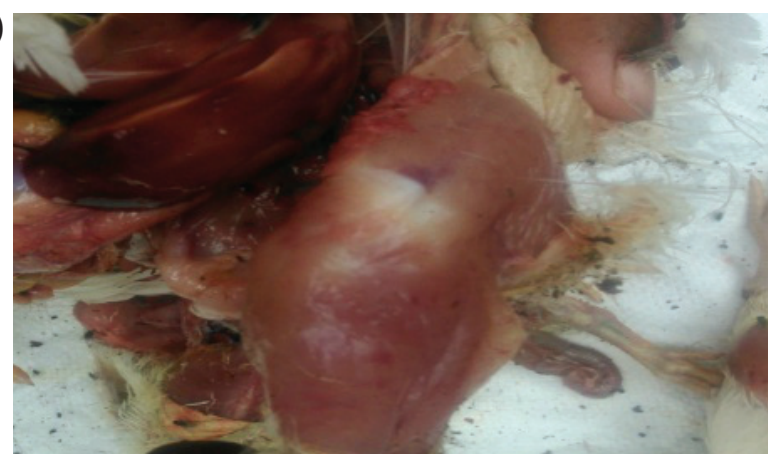

Fig. 2

Gross pathological changes of IBDV-infected birds

(a) Severe bursal hemorrhages; (b) Severe paint brush hemorrhages in the thigh muscle.

\section{Histopathology}

The average bursa: body weight ratios were markedly reduced in birds inoculated with MB11, HY12, PY12, VCN14, BGE14, and NKL14 compared with uninoculated control group as shown in Table 1 . There were significant differences in the groups infected with isolates when compared to control group $(\mathrm{P}<0.05)$. There were significant differences in the groups inoculated with PY12 and RPM14 when compared to the groups inoculated with isolate EDE14 $(\mathrm{P}<0.05)$. The groups inoculated with BGE14, VCN14, HY12, NKL14 did not differ significantly from each other. In spleen index, there were significant differences in the groups infected with isolates HY12, EDE14, RPM14 when compared to control group. The histological evaluation of the bursa showed marked bursal lymphoid necrosis and depletion in the infected groups, and significant differences were found in bursal lesion scores when compared with the uninoculated control groups. No observable significant lesions and bursal scoring lesions were present in the control birds throughout the trial. The isolates HY12, PY12, BGE14, VCN14, NKL14, RPM14 and EDE14 at day 5 post inoculation showed severe lymphoid necrosis and depletion both in the medulla and cortex of the follicles in the bursal tissues. Mild hemorrhage was also present in some follicles and within the interstitial connective tissue (Fig. 3).

Nucleotide and amino acid sequence analysis of IBDV isolates

The region analyzed included 145 amino acid residues from 252 to 397 of the segment A polyprotein. When compared with European strain 52/70, the following amino acid changes were observed within the hypervariable region of the VP2. Glutamine was substituted by histidine at residue 253 in the classical MB11 isolate. The amino acid substitution of isoleucine for valine was observed in the isolates BGE14, HY12, PY12, NKL14, VCN14, RPM14 and EDE14, whereas MB11 isolate did not have this change at the position 256. Alanine was substituted by threonine at the amino

Table 1. Grading, Bursa:Body weight, Spleen:Body weight ratios and mortality following inoculation of $1 \times 10^{6} \mathrm{TCID}_{50}$ infectious bursal disease virus at $5^{\text {th }}$ day of post inoculation (mean \pm S.D.)

\begin{tabular}{lllll}
\hline Virus isolates & Grading & Spleen index & Bursal index & Mortality \\
\hline BGE14 & Severe & $0.455 \pm 0.05^{\mathrm{ab}}$ & $0.472 \pm 0.07^{\mathrm{abc}}$ & $40(2 / 5)$ \\
NKL14 & Severe & $0.573 \pm 0.07^{\mathrm{abc}}$ & $0.483 \pm 0.12^{\mathrm{abc}}$ & $20(1 / 5)$ \\
VCN14 & Severe & $0.526 \pm 0.20^{\mathrm{abc}}$ & $0.482 \pm 0.14^{\mathrm{abc}}$ & $20(1 / 5)$ \\
EDE14 & Severe & $0.397 \pm 0.33^{\mathrm{ab}}$ & $0.564 \pm 0.06^{\mathrm{bc}}$ & $20(1 / 5)$ \\
RPM14 & Severe & $0.455 \pm 0.29^{\mathrm{ab}}$ & $0.365 \pm 0.08^{\mathrm{a}}$ & No mortality \\
MB11 & Mild to moderate & $0.518 \pm 0.13^{\mathrm{abc}}$ & $0.421 \pm 0.03^{\mathrm{ab}}$ & $20(1 / 5)$ \\
HY12 & Severe & $0.350 \pm 0.09^{\mathrm{a}}$ & $0.482 \pm 0.12^{\mathrm{abc}}$ & No mortality \\
PY12 & Severe & $0.537 \pm 0.13^{\mathrm{abc}}$ & $0.333 \pm 0.07^{\mathrm{a}}$ & No mortality \\
Control & Normal & $0.749 \pm 0.05^{\mathrm{c}}$ & $0.854 \pm 0.10^{\mathrm{d}}$ & \\
\hline
\end{tabular}

Results are expressed as mean \pm S.D. Means in the same column with same superscript did not differ significantly $(\mathrm{P}<0.05)$. 
(a)

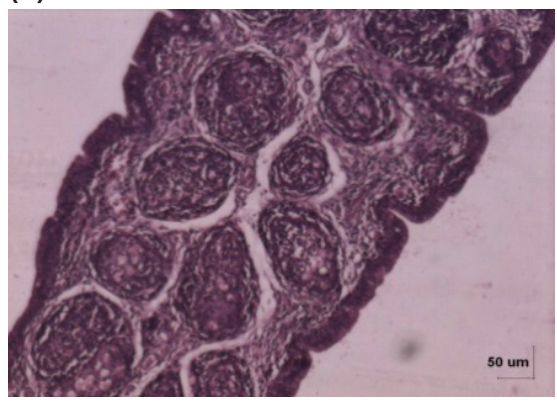

(b)

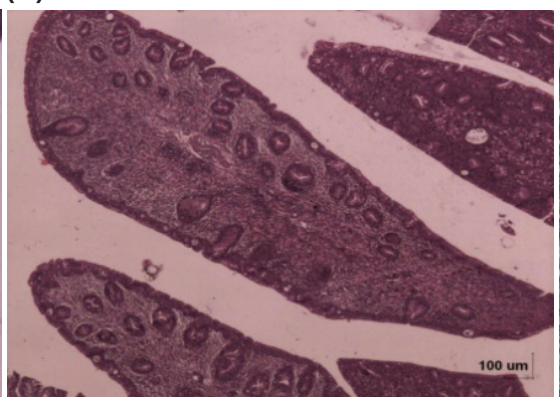

(c)

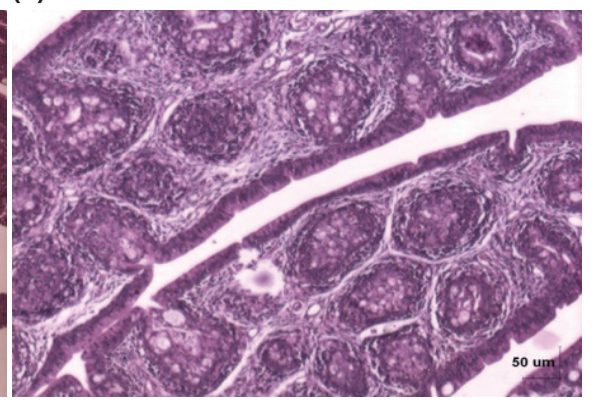

Fig. 3

Bursal tissue section stained with $\mathrm{H} \& \mathrm{E}$

(a) BGE14 isolate caused severe lymphoid depletion in bursa; (b) NKL14 isolate produced follicular atrophy and interstitial cell fibrosis of bursa; (c) Normal lymphoid follicles from uninfected bird.

acid position of 270 in the MB11 isolate, and isoleucine was substituted by threonine at residue 272 in the HY12 isolate. Aspartic acid was substituted by asparagine at residue 279 in MB11 and in HY12 isolates of IBDV. Alanine was substituted by threonine at residue 284 in MB11 isolate. Leucine was substituted by isoleucine at residue 294 in PY12 isolate, other very virulent isolates have the substitution of valine and the classical isolate MB11 did not have this substitution. Asparagine was substituted by serine in all very virulent isolates and was not observed in the classical isolate of MB11 at residue 299. Glutamic acid was substituted by alanine in all very virulent isolates except very virulent isolate HY12 and classical isolate MB11 at residue 300. The serine-rich heptapeptide sequence SWSASGS adjacent to the second hydrophilic region was conserved among all the Indian IBDV isolates except MB11.

The identity matrix of nucleotides and amino acids of the isolate MB11 (classical strain) and other very virulent isolates of this study were compared to highly similar isolates 52/70 and UK661, respectively, from GenBank. Classical strain (MB11) had highest nucleotide similarity of $96.7 \%$ with both $52 / 70$ and STC and had highest amino acid $96.3 \%$ with STC and $96 \%$ with $52 / 70$. The pairwise sequence analysis of different very virulent isolates of IBDV shows highest nucleotide and amino acid similarity for BGE14 - 96.1\%, EDE14 - 95.5\%, HY12 - 98\%, NKL14 - 95.5\%, PY12 - 96.9\%, RPM14 - 96.9\% and VCN14 - 96.8\% and BGE14 - 98.6\%, EDE14 - 98.5\%, HY12 - 98.8\%, NKL14 - 95.1\%, PY12 - 98.3\%, RPM14 $98.6 \%$ and VCN14 - 98.6\%, respectively, in comparison with UK661. Nucleotide and amino acid sequence identity and divergence are shown in table 2 and 3, respectively.

\section{Phylogenetic analysis}

Based on the nucleotide sequence analysis, all isolates except MB11 were grouped in the same cluster along with already reported very virulent European and Japanese isolates, indicating their close evolutionary relationship. Among the classical strains, European strain 52/70 was closer to Indian field isolates than any other classical, variant or attenuated strain as reported by earlier works (Brown et al., 1994; Yamaguchi et al., 1997; Kataria et al., 2001). Phylogenetic analysis revealed 5 distinct branches in the phylogenetic tree with 1000 bootstrap replication. Isolates RPM14, EDE14, VCN14, PY12, BGE14 and NKL14 formed a separate clad close to very virulent strains of other Indian isolates. Whereas isolate HY12 formed a separate clad, found close to other very virulent isolates such as OKYM, TN1/93, JK1/97, Is-KS, UK661 and HR1/96. The MB11 isolate was grouped with the classic strains such as STC, 52-70, Cu-1, PBG and variant strain GLS (Fig. 4).

\section{Antigenic index}

Potential antigenic sites within the predicted 145 amino acid hypervariable region were compared by calculating an 'antigenic index' that reflects the influence of several different parameters such as hydrophilicity, surface probability, backbone flexibility and secondary structure prediction (Jameson and Wolf, 1988). Significant differences in the 'antigenic index' profile between classical, virulent and very virulent IBDV s have been previously determined in the hypervariable region. In our studies, classical strain 52/70 showed missing antigenic peak number 1,8 and 9 when compared with MB11 isolate. Comparison of very virulent Indian isolates with UK661 revealed that except HY12, the other very virulent isolates showed missing antigenic site at number 1. The isolates NKL14, UK661 and EDE14 showed missing antigenic peak identified at number 7 and 8 and HY12 isolate showed missing antigenic peak at number 8 when compared with BGE14 

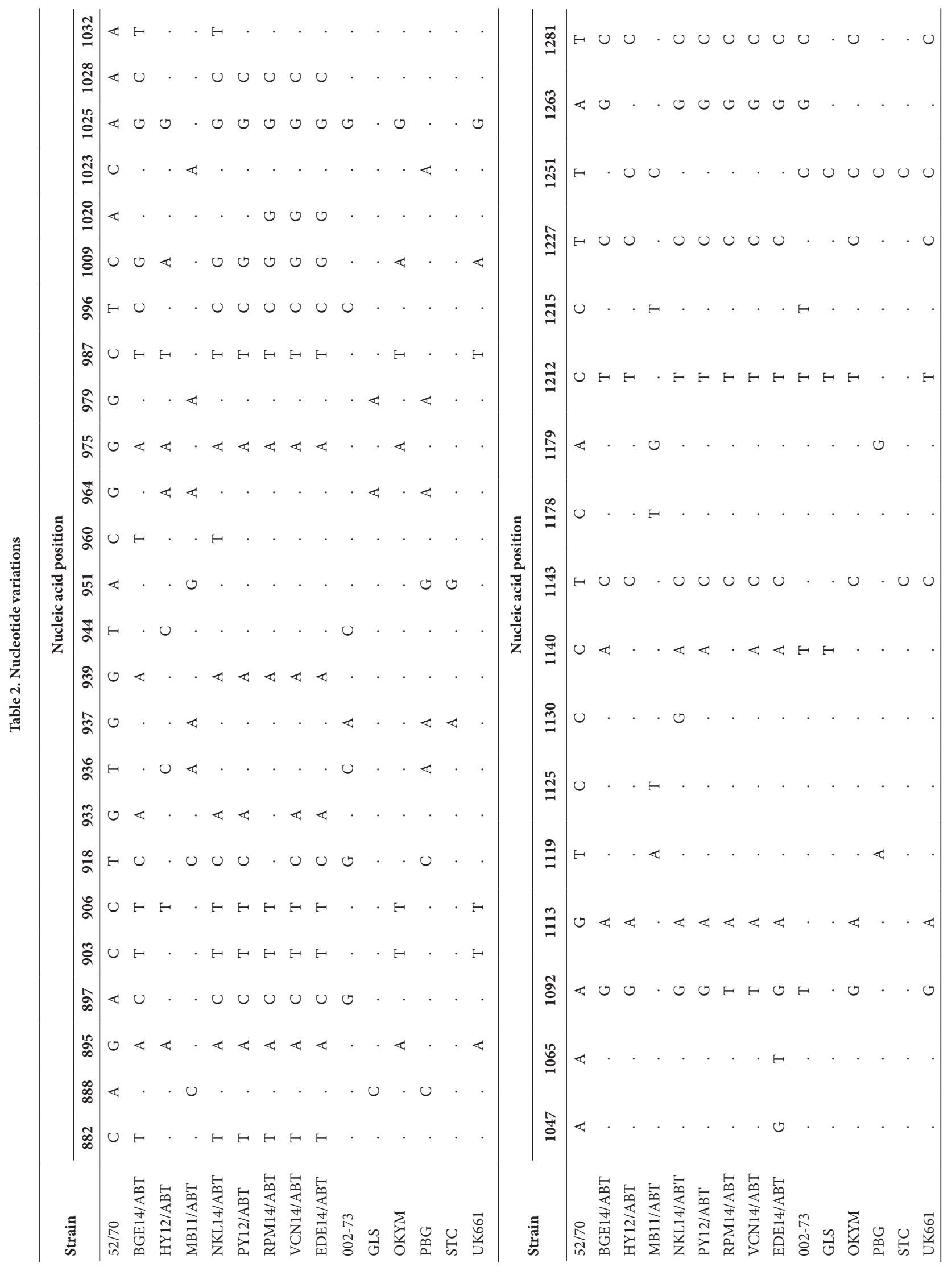
Table 3. Amino acid variations

\begin{tabular}{|c|c|c|c|c|c|c|c|c|c|c|c|c|}
\hline \multirow{2}{*}{ Strain } & \multicolumn{12}{|c|}{ Amino acid position } \\
\hline & 253 & 256 & 270 & 272 & 279 & 284 & 294 & 299 & 300 & 330 & 334 & 350 \\
\hline $52 / 70$ & Q & $\mathrm{V}$ & A & I & $\mathrm{D}$ & A & $\mathrm{L}$ & $\mathrm{N}$ & $\mathrm{E}$ & S & A & $\mathrm{T}$ \\
\hline BGE14/ABT & . & I & . & . & . & . & $\mathrm{V}$ & S & A & . & . & . \\
\hline HY12/ABT & . & I & . & $\mathrm{T}$ & $\mathrm{N}$ & . & I & S & . & . & . & . \\
\hline MB11/ABT & $\mathrm{H}$ & . & $\mathrm{T}$ & . & $\mathrm{N}$ & $\mathrm{T}$ & . & . & . & $\mathrm{R}$ & . & M \\
\hline NKL14/ABT & . & I & . & . & . & . & $\mathrm{V}$ & S & $\mathrm{A}$ & . & G & . \\
\hline $\mathrm{PY} 12 / \mathrm{ABT}$ & . & I & . & . & . & . & $\mathrm{V}$ & S & $\mathrm{A}$ & . & . & . \\
\hline RPM14/ABT & . & I & . & . & . & . & $\mathrm{V}$ & S & $\mathrm{A}$ & . & . & . \\
\hline VCN14/ABT & . & I & . & . & . & . & $\mathrm{V}$ & S & $\mathrm{A}$ & . & . & . \\
\hline EDE14/ABT & . & I & . & . & . & . & $\mathrm{V}$ & . & . & . & . & . \\
\hline $002-73$ & . & . & $\mathrm{T}$ & $\mathrm{T}$ & G & . & . & S & . & . & . & . \\
\hline GLS & $\mathrm{H}$ & . & . & . & $\mathrm{N}$ & $\mathrm{T}$ & . & . & . & . & . & . \\
\hline OKYM & . & I & . & . & . & . & I & S & . & . & . & . \\
\hline PBG-98 & $\mathrm{H}$ & . & $\mathrm{T}$ & . & $\mathrm{N}$ & $\mathrm{T}$ & . & . & . & $\mathrm{R}$ & . & . \\
\hline STC & . & . & $\mathrm{T}$ & . & . & . & . & . & . & . & . & . \\
\hline UK661 & . & I & . & . & . & . & I & S & . & . & . & . \\
\hline
\end{tabular}

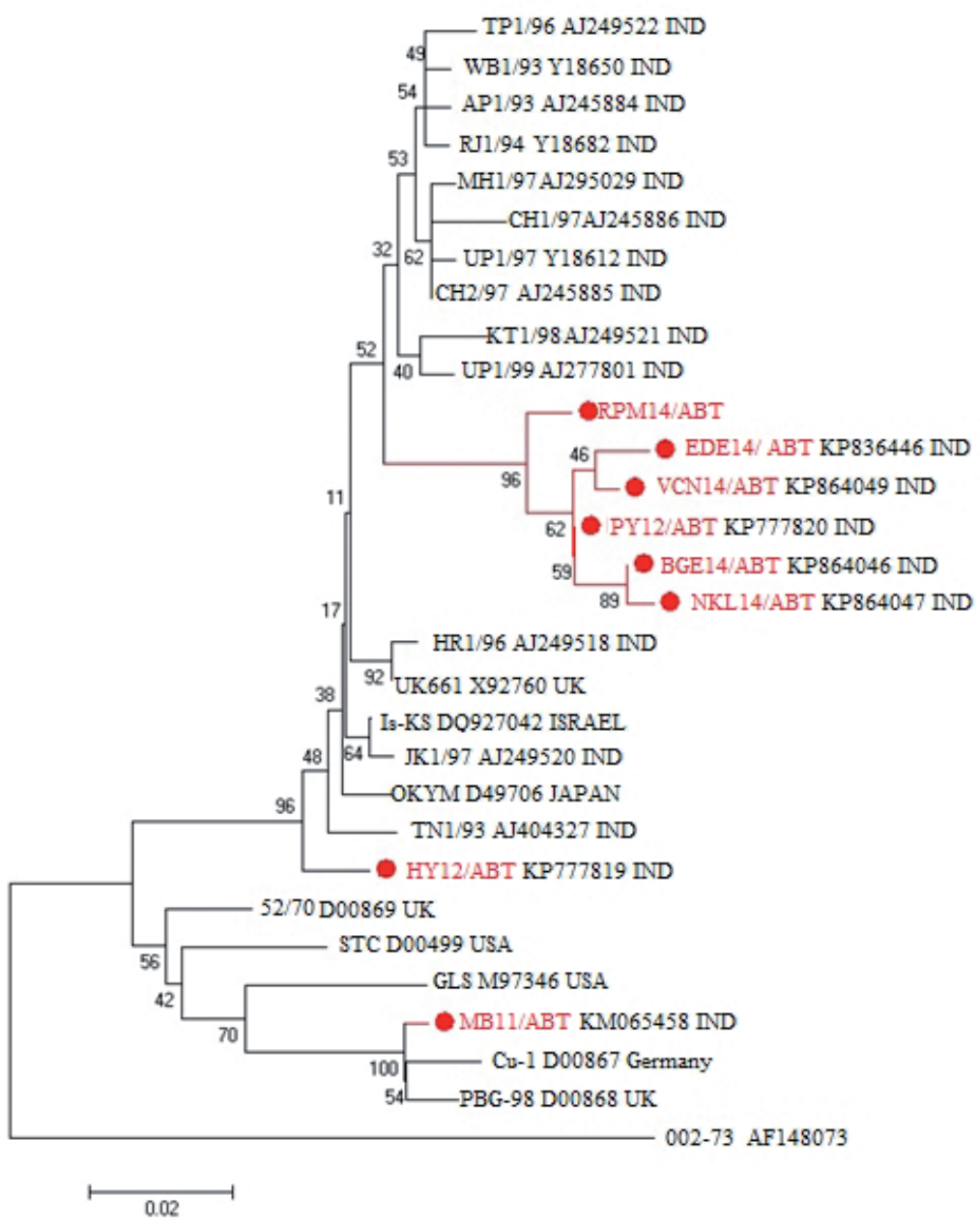

Fig. 4

Phylogenetic analysis based on partial segment A sequence of IBDV 


\section{Classical Strains of IBDV}

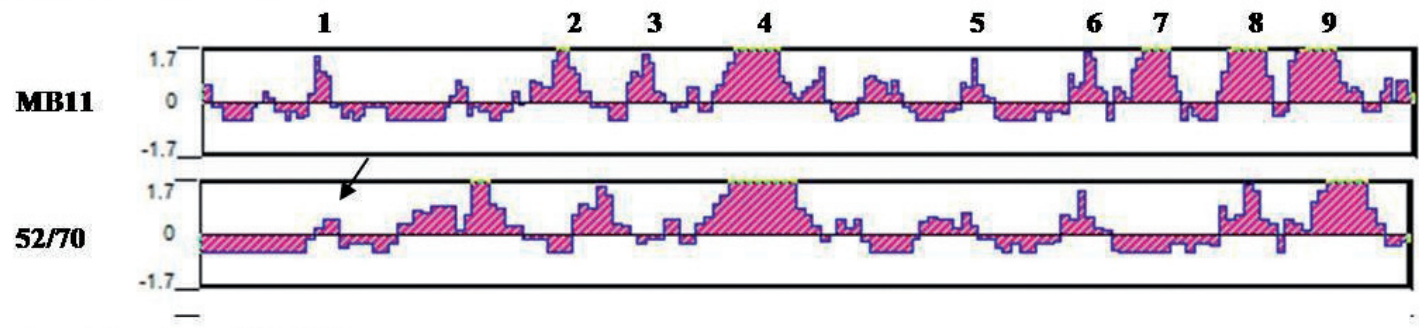

\section{Very Virulent Strains of IBDV}

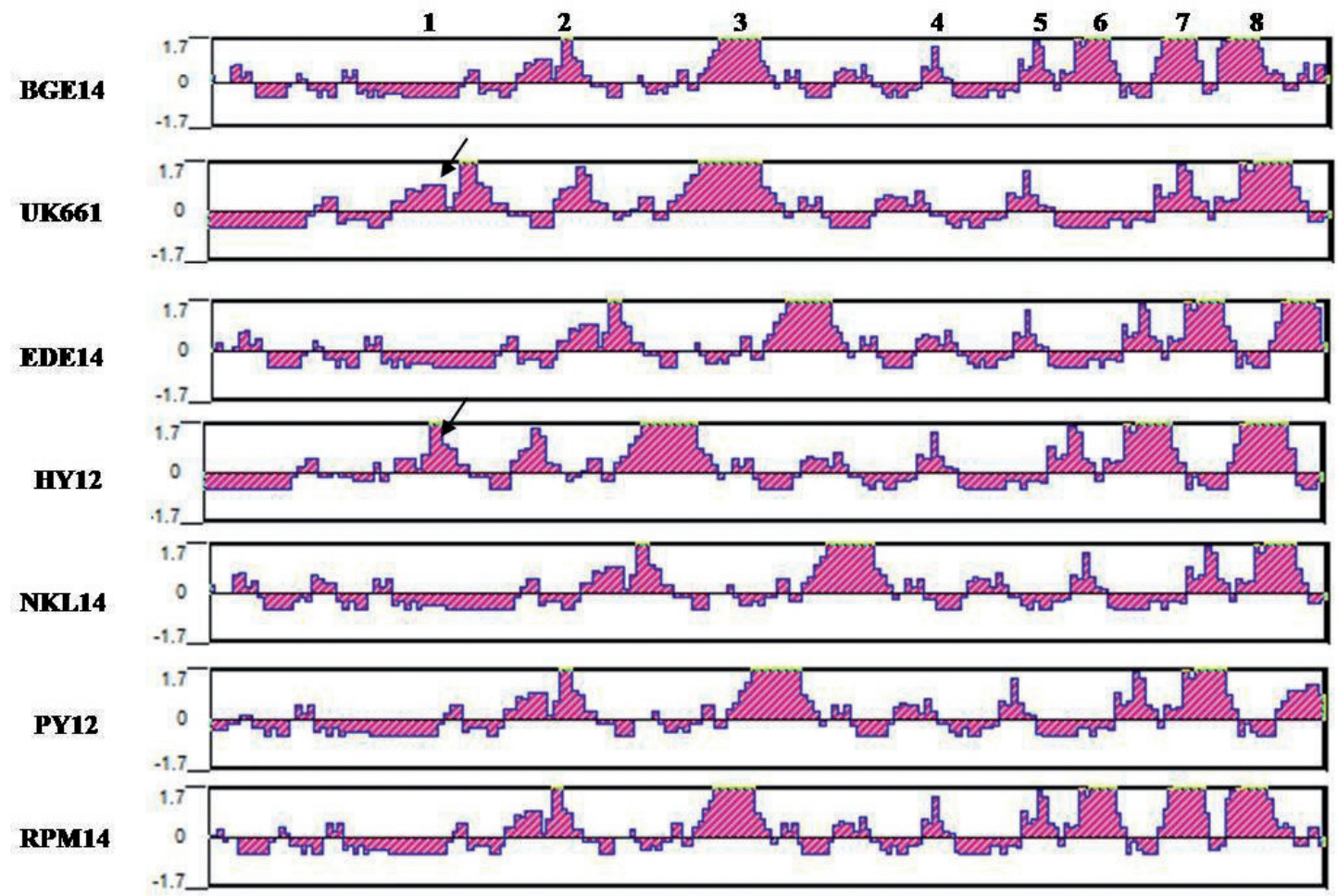

Fig. 5

Antigenic index analysis in VP2 gene of the IBDV isolates

Peaks identified as potential antigenic sites within the deducted amino acid sequence of the hypervariable region of VP2 gene from amino acid residues 252 to 397. Eight IBDV isolates are being compared with European classical virulent and UK 661 very virulent strains. The classical MB11 isolate has 9 major antigenic peaks. The classical 52/70 strains show missing antigenic peaks number 1, 8 and 9 and there are changes in the topography of the major antigenic peak of MB11 isolate. The very virulent strain BGE14 shows 7 major antigenic peaks when compared to UK661 isolates. Except the very virulent UK661 and HY12 isolates, remaining vvIBDV isolates show the missing antigenic peak number 1 when compared to other very virulent isolates. The NKL14, UK661 and EDE14 show missing antigenic peak that was identified at number 7 and 8, HY12 isolate show missing antigenic peak at number 8.

isolate, which is having 7 major antigenic sites showed in Fig. 5.

\section{Discussion}

One of the major problems observed in the poultry farms of India are the frequent outbreaks of IBD in spite of the extensive use of available IBD vaccines. This failure in vaccination could be due to the genetic drift or mutations observed in VP2 (which is a major protective antigen of IBDV) that may result from immunological pressure or genetic reassortment between more than one strain (Hon et al., 2006). In this study, bursal tissues collected from different states of southern India were subjected to RT-PCR using primers specific for variable region in the VP2 gene of IBDV, and isolations in CEF cells. The VP2 gene of IBDV was targeted to determine the prevalence and to track evolution- 
ary changes at the molecular level by sequencing. Molecular evaluation of the hypervariable region of the chosen eight isolates were studied to compare their nucleotide and amino acid sequences with other Indian IBDV isolates and isolates from other parts of the world. The multiple alignment and phylogenetic analysis of the hypervariable domain of the VP2 region helped to group the IBDV isolates into different pathogenic subgroups.

The serine-rich heptapeptide sequence SWSASGS adjacent to the second hydrophilic region was conserved among all the Indian IBDV isolates except MB11. Conservation of this sequence was earlier reported to be an indication of a virus isolate being pathogenic in nature (Vakharia et al., 1994). Lim et al. (1999) identified the minimal changes (279D-N and $284 \mathrm{~A}-\mathrm{T}$ ) responsible for tissue culture adaptation and concomitant attenuation of vvIBDV by in vitro mutagenesis without need to change the 'SWSASGS' heptapeptide. In the present study, the isolates HY12 and MB11 showed mutational changes at 279D-N and isolate MB11 had changes also at 284A-T. It was found that the isolates BGE14, HY12, PY12, NKL14, VCN14, RPM14 and EDE14 are not of vaccinal or attenuated origin due to the absence of 253 Histidine and 284 threonine mutations that are typically found in attenuated vaccine strains (Jackwood et al., 2008). Yuwen et al. (2008) reported that the serine rich heptapeptide SWSASGS was the conserved marker amino acids of vvIBDVs, which was different for classical, attenuated, vaccine and variant strains as 222T (P or Q), 256V, 294L and 299N. The heptapeptide of the attenuated and vaccine strain is SWSARGS (Eterradossi et al. 1999). In the present study, 'SWSARGS' heptapeptide sequence was observed only in the isolate MB11.

All the isolates had glycine at residue 254 as this was the characteristic of standard IBDV strains. Leucine was substituted by isoleucine at residue 294 in PY12 isolate. But other Indian very virulent isolates and isolates from other parts of the world are having valine residue in place of leucine. Substitution of isoleucine at residue 294 had not been reported earlier from India in any pathotypes of IBDV viruses. Similar amino acid change has also been reported by Banda et al. (2001) in isolate 9109 from United States and it was concluded that the clinical significance of this substitution at residue 294 in the protein sequence of the 9109 isolate was not clear. The poor performance and recurrent respiratory problems of broiler flock were correlated with the presence of IBDV 9109 isolate in the flock, most likely as the consequences of immunosuppression. However, the birds did not exhibit clinical signs or mortality rates characteristic of vvIBDV strains. The preliminary clinical studies in SPF birds and commercial broilers with 9109 isolate produced a subclinical form of IBDV with bursal atrophy.

The mutations in the very virulent isolates reported earlier by Cao et al. (1998) and Eterradossi et al. (1999) at 256V-I, 294L-I and 299N-S were conserved in all Indian isolates of vvIBDV including the isolates of present study, whereas MB11 isolate had valine at 256, like other classical strains of IBDV. Asparagine was substituted by serine in all very virulent isolates at residue 299 and the same was not observed in the classical isolate MB11.

All vvIBDV isolates have alanine residue at 300, except vvIBDV isolate HY12 and classical isolate MB11. The HY12 and MB11 isolates have glutamic acid at residue 300. Mohamed et al. (2014) also reported the presence of alanine residue at 300 in the vvIBDV isolates from Bangladesh, Nigeria, India and Nepal. Glutamic acid is characterized by negatively charged (acidic) R group, whereas, the R group in alanine is non polar (hydrophobic). It is probable that this change from negative charge to non-polar may modify the protein folding or the interaction with other molecules that may change the topography of the neutralizing epitopes that may lead to vaccination failure (Jackwood et al., 2011).

De Paula et al. (2004) also reported the presence of serine at position 299 in BR-GO strain (Brazil). However, they didn't observe this change exclusively in all vvIBDV strains. On the other hand, Chong et al. (2001) stated that the asparagine to serine substitution at the amino acid position 299 and alanine to glutamic acid substitution at position 300 were not related to pathogenicity of the strains, although serine at position 299 was observed in many vvIBDV strains.

Raus et al. (2013) reported that among five amino acid residues, only A (222) was located at hydrophilic region of VP2 variable region. Other amino acids I (242), I (256), I (294) and S (299), though they were closely located, are not directly in hydrophilic regions and are believed to be still in the projection domains in VP2. Amino acid residues A (222), I (256) and I (294) were reported to be unique residues, which had been used as the indication of the very virulent subtypes. IBDV isolates, which carry at least these 3 amino acid residues, are categorized as very virulent subtypes. When compared with attenuated viruses, there were differences at the positions 253, 279, 284, 290 and 330 of very virulent viruses. Among these five, the amino acids at positions 253, 279 and 284 were confirmed to be important marker for the virulence, cell tropism and pathogenic phenotypes (Brandt et al., 2001). The same finding was also reported by van Loon et al. (2002), and they observed the change of the amino acids at positions 253 and 284 in both tissue culture adaptation and virus attenuation in SPF chickens. According to Coulibaly et al. (2005), these three amino acids at positions 253, 279 and 284 were located in the most exposed loops of the projection domain that had direct interaction with immune system. However, Boot et al. (2000) found that the changes of VP2 in attenuated IBDV with very virulent pathotypes showed that no mortality and morbidity could be observed. Previous studies indicated that few of Indian IBDV isolates were similar to very virulent IBDV from European and other Asian countries and it was 
postulated that vvIBDV strains would have entered India from northern and eastern parts, probably from China and South East Asia (Kataria et al., 2001). Complete genome sequencing of these isolates and classical viruses would provide more information on virus characteristics.

Phylogenetic analysis revealed that most of the isolates are more closely related to the very virulent UK661 isolate than any other classical and vaccine strains. As reported earlier by Ramadass et al. (2003), the sequence analysis indicated that presence of mixed type of IBDV infection in southern states of India poses a problem in the institution of vaccination regimen in the control of IBD. Jenberie et al. (2013) reported that the Ethiopian vvIBDV clustered with African IBDV genetic lineage, independent of the Asian / European IBDV lineage. Nwagbo et al. (2016) studied the genetic diversity of IBDV in Nigeria by sequencing the VP2 and VP1 region and they reported a new lineage of Nigerian reassortant IBDV strains.

The potential antigenic sites were also reported by Lana et al. (1992), who found that the variant A virus was missing a peak in the antigenic index within the hypervariable domain (amino acids 284-288) that is present in all other classical viruses. Banda et al. (2001) reported that five isolates $(619,625,849,850$ and 11153) exhibited identical antigenic profile indexes to that of variant $\mathrm{E}$ strain and another isolate (9109) exhibited a profile similar to that of the STC strain. Mohamed et al. (2014) reported the missing antigenic peaks number 4 and 2 in strains 3 and 4, respectively, as well as changes in the topography of major antigenic peaks in strains 4 and 7 when compared to UK661.

In conclusion, the results show that the eight isolates from different states of southern India share similar origins with vvIBDV s of Asia and Europe. The isolate MB11, which has the serine rich heptapeptide sequence 'SWSARGS', shares the origin with classical virulent IBDV as indicated by other determinants in the partial VP2 hypervariable region. Though the isolate HY12 carries the heptapeptide 'SWSASGS', it also exhibits variations in the VP2 determinant regions. The in vivo study also reveals the very virulent nature of all the isolates except MB11, which exhibits the classical virulent feature of IBDV. Furthermore, complete genome sequencing of these isolates and classical viruses would provide more information on virus characteristics and evolution.

Acknowledgment. The work was supported by the Indian Council of Agricultural Research funding in the form of Niche area of Excellence on Molecular diagnostics and vaccines for avian diseases [grant number 21141] in Animal Biotechnology.

\section{References}

Banda A, Villegas P, El-Attrache J, Estevez C (2001): Molecular characterization of seven field isolates of infec- tious bursal disease virus obtained from commercial broiler chickens. Avian Dis. 45, 620-630. https://doi. org/10.2307/1592903

Bayliss CD, Spies U, Shaw K, Peters RW, Papageorgiou A, Muller H, Boursnell MEG (1990): A comparison of the sequences of segment $\mathrm{A}$ of four infectious bursal disease virus strains and identification of a variable region in VP2. J. Gen. Virol. 71, 1303-1312. https://doi.org/10.1099/00221317-71-6-1303

Brandt M, Yao K, Liu M, Heckert RA, Vakharia VN (2001): Molecular determinants of virulence, cell tropism, and pathogenic phenotype of infectious bursal disease virus. J. Gen. Virol. 75, 11974-11982. https://doi.org/10.1128/ JVI.75.24.11974-11982.2001

Brown MD, Green P, Skinner MA (1994): VP2 sequences of recent European 'very virulent' isolates of infectious bursal virus are closely related to each other but are distinct from those of 'classical' strains. J. Gen. Virol. 75, 675-680. https://doi. org/10.1099/0022-1317-75-3-675

Cao YC, Yeung WS, Law M, Bi YZ, Leung FC, Lim BL (1998): Molecular characterization of seven Chinese isolates of infectious bursal disease virus: classical, very virulent, and variant strains. Avian Dis. 2, 340-351. https://doi. org/10.2307/1592484

Chong LK, Omar AR, Yusoff K, Hair-Bejo M, Aini I (2001): Nucleotide sequence and phylogenetic analysis of A segment of a highly virulent strain of infectious bursal disease virus. Acta Virol. 45, 217-226.

Coulibaly F, Chevalier C, Gutscheetal I (2005): The birnavirus crystal structure reveals structural relationships among icosahedral viruses. Cell 120, 761-772. https://doi. org/10.1016/j.cell.2005.01.009

De Paula MBC, Yokosawa J, Coutinho MDB (2004): Identification and molecular characterization of the infectious bursal disease virus (IBDV) from in outbreak in a broiler flock in Midwestern Brazil. Braz. J. Microbiol. 35, 352-358. https://doi.org/10.1590/S1517-83822004000300016

Delmas B (2005): Birnaviridae. In Fauquet CM, Mayo MA, Maniloff J, Desselberger U, Ball LA (Eds): Virus Taxonomy, 8th Report of the International Committee on Taxonomy of Viruses. Elsevier Academic, London, 561-569.

Dobos P (1979): Peptide map comparison of the proteins of infectious bursal disease virus. J. Virol. 32, 1046-1050.

Durairaj V, Sellers HS, Linnemann EG, Icard AH, Mundt E (2011): Investigation of the antigenic evolution of field isolates using the reverse genetics system of infectious bursal disease virus (IBDV). Arch. Virol. 156, 1717-1728. https://doi. org/10.1007/s00705-011-1040-x

Eterradossi N, Arnauld C, Tekaia F, Toquin D, Le Coq H, Rivallan G, Guittet M, Domenech J, van den Berg TP, Skinner MA (1999): Antigenic and genetic relationships between European very virulent Infectious Bursal Disease Viruses and an early West African isolate. Avian Pathol. 28, 36-46. https://doi.org/10.1080/03079459995028

Fahey KJ, Erny K, Crooks J (1989): A conformational immunogen on VP2 of infectious bursal disease virus that induces virus-neutralizing antibodies that passively 
protect chickens. J. Gen. Virol. 70, 1473-1481. https:// doi.org/10.1099/0022-1317-70-6-1473

Heine HG, Haritou M, Failla P, Fahey KJ, Azad AA (1991): Sequence analysis and expression of the host-protective immunogen VP2 of a variant strain of infectious bursal disease virus which can circumvent vaccination with standard serotype 1 strains. J. Gen. Virol. 72, 1835-1843. https:// doi.org/10.1099/0022-1317-72-8-1835

Hon CC, Lam TY, Drummond A (2006): Phylogenetic analysis reveals a correlation between the expansion of very virulent infectious bursal disease virus and reassortment of its genome segment B. J. Virol. 80, 8503-8509. https:// doi.org/10.1128/JVI.00585-06

Jackwood DJ, Saif YM, Moorhead PD (1985): Immunogenicity and antigenicity of infectious bursal disease virus serotypes 1 and 2 in chickens. Avian Dis. 29, 1184-1194. https://doi. org/10.2307/1590472

Jackwood DH, Saif YM (1987): Antigenic diversity of infectious bursal disease viruses. Avian Dis. 31, 766-770. https:// doi.org/10.2307/1591028

Jackwood DJ, Sommer-Wagner SE (2005): Molecular epidemiology of infectious bursal disease viruses: distribution and genetic analysis of newly emerging viruses in the United States. Avian Dis. 49, 220-226. https://doi. org/10.1637/7289-101404R

Jackwood DJ, Sreedevi B, LeFever LJ, Sommer-Wagner SE (2008): Studies on naturally occurring infectious bursal disease viruses suggest that a single amino acid substitution at position 253 in VP2 increases pathogenicity. Virology 377 , 110-116. https://doi.org/10.1016/j.virol.2008.04.018

Jackwood DJ, Sommer-Wagner SE, Crossley BM, Stoute ST, Woolcock PR, Charlton BR (2011): Identification and pathogenicity of a natural reassortant between a very virulent serotype 1 infectious bursal disease virus (IBDV) and a serotype 2 IBDV. Virology 420, 98-105. https://doi. org/10.1016/j.virol.2011.08.023

Jameson BA, Wolf H (1988): The antigenic index: a novel algorithm for predicting antigenic determinants. Comput Appl Biosci. 4, 181-186. https://doi.org/10.1093/ bioinformatics/4.1.181

Jenberie S, Lynch SE, Kebede F, Christely RM, Gelaye E, Negussie H, Asmare K, Ayelet G (2014): Genetic characterization of infectious bursal disease virus isolates in Ethiopia. Acta Trop. 130, 39-43. https://doi.org/10.1016/j. actatropica.2013.09.025

Kataria RS, Tiwari AK, Butchaiah G, Kataria JM (1999): Differentiation of infectious bursal disease virus strains by restriction enzyme analysis of RT-PCR amplified VP2 gene sequences. Acta Virol. 43, 243-249.

Kataria RS, Tiwari AK, Butchaiah G, Kataria JM, Skinner MA (2001): Sequence analysis of the VP2 gene hypervariable region of infectious bursal disease viruses from India. Avian Pathol. 30, 501-507. https://doi.org/10.1080/03079450120078699

Lana DP, Beisel CE, Silva R (1992): Genetic mechanisms of antigenic variation in infectious bursal disease virus: analysis of a naturally occurring variant virus. Virus Genes. 6, 247-259. https://doi.org/10.1007/BF01702563
Lillie RD (1965): Histologic Technique and Practical Histochemistry3rd edn. New York, McGraw Book Company.

Lim BL, Cao Y, Yu T, Mo CW (1999): Adaptation of very virulent IBDV to chicken embryonic fibroblasts by site-directed mutagenesis of residues 279 and 284 of viral coat protein VP2. J. Virol. 73, 2854-2862.

Lin TL, Wu CC, Rosenberger JK, Saif YM (1994): Rapid differentiation of infectious bursal disease virus serotypes by polylmerase chain reaction. J. Vet. Diag. Invest. 6, 100-102. https://doi.org/10.1177/104063879400600119

Liu M, Vakharia VN (2004): VP1 protein of infectious bursal disease virus modulates the virulence in vivo. Virology 330, 62-73. https://doi.org/10.1016/j.virol.2004.09.009

Mac Donald RD (1980): Immunofluorescent detection of doublestranded RNA in cells infected with reovirus, infectious pancreatic necrosis virus, and infectious bursal disease virus. Can. J. Microbiol. 26, 256-261. https://doi.org/10.1139/ $\underline{\mathrm{m} 80-040}$

McFerran JB, McNutly M, McKilliop ER, Conner TJ, McCracken RM, Collins DS, Allan GM (1980): Isolation and serological studies with infectious bursal disease virus from fowl, turkeys and ducks: demonstration of a second serotype. Avian Pathol. 9, 395-404. https://doi. org/10.1080/03079458008418423

Mohamed MA, Elzanaty KES, Bakhit BM, Safwat MM (2014): Genetic Characterization of Infectious Bursal Disease Viruses Associated with Gumboro Outbreaks inin Commercial Broilers from Asyut Province, Egypt. International Scholarly Research Notices : Veterinary Science, 1-9.

Muller H, Nitschke N (1987): The two segments of infectious bursal disease virus genome are circularized by a 90,000 Da protein. Virology 159, 174-177. https://doi. org/10.1016/0042-6822(87)90363-1

Muskett JC, Hopkins IG, Edwards KR, Thornton DH (1979): Comparison of two infectious bursal disease vaccine strains: efficacy and potential hazards in susceptible and maternally immune birds. Vet. Rec. 104, 332-334. https:// doi.org/10.1136/vr.104.15.332

Nwagbo IO, Shittu I, Nwosuh CI, Ezeifeka GO, Odibo FJC, Michel LO, Jackwood DJ (2016): Molecular characterization of field infectious bursal disease virus isolates from $\mathrm{Ni}$ geria. Vet. World. 9, 1420-1428. https://doi.org/10.14202/ vetworld.2016.1420-1428

Ramadass P, Thiagarajan V, Parthiban M, Senthilkumar TMA, Latha D, Anbalagan S, Krishnakumar M, Nachimuthu K (2003): Sequence analysis of infectious bursal disease virus isolates from India: phylogenetic relationships. Acta Virol. 47, 131-135.

Raus RA, Ghazali MS, Amin NM, Shohaimi SA, Abu Bakar FD, Zainuddin NB, Muhammad NAAN (2013): Genomic analysis and comparison of very virulent infectious bursal disease virus (vvIBDV) affecting Malaysian poultry chickens with other IBDV strains. Ann. Biol. Res. 4, 92-104.

Rodriguez-Chavez IR, Rosenberger JK, Cloud SS (2002): Characterization of the antigenic, immunogenic, and pathogenic variation of infectious bursal disease virus due to propagation in different host systems 
(bursa, embryo, and cell culture). I. Antigenicity and Immunogenicity. Avian Pathol. 31, 463-471. https://doi. org/10.1080/0307945021000005833

Rosenberger JK, Cloud SS, Gelb J, Odor E, Dohms JE (1985): Sentinel bird survey of Delmarva broiler flocks. Proceedings of the 20th National Meeting on Poultry Health and Condemnations, Ocean City, MD, 94-101.

Saif YM (1991): Immunosuppression induced by infectious bursal disease virus. Vet. Immunol. Immunop. 30, 45-50.

Schnitzier D, Bernstein F, Muller H, Becht H (1993): The genetic basis for the antigenicity of the VP2 protein of the infectious bursal disease virus. J. Gen. Virol. 74, 1563-1571. https://doi.org/10.1099/0022-1317-74-8-1563

Synder DB, Lana DP, Savage PK, Yancey FS, Mengel SA, Marquardt WW (1988): Differentiation of infectious bursal disease viruses directly from infected tissues with neutralizing monoclonal antibodies: Evidence of a major antigenic shift in recent field isolates. Avian Dis. 32, 535-539. https://doi.org/10.2307/1590924

Tanimura N, Tsukamoto K, Nakamura K, Narita M, Maeda M (1995): Association between pathogenicity of infectious bursal disease virus and viral antigen distribution detected by immunohistochemistry. Avian Dis. 39, 9-20. https:// doi.org/10.2307/1591976

Vakharia V, He N, Ahamed B, Snyder DB (1994): Molecular basis of antigenic variation in infectious bursal disease virus. Virus Res. 31, 264-273. https://doi.org/10.1016/01681702(94)90009-4

van den Berg TP (1991): Acute infectious bursal disease in poultry: isolation and characterization of a highly virulent strain. Avian Pathol. 20, 409-421. https://doi. org/10.1080/03079459108418779

Yamaguchi T, Ogawa M, Miyoshi M, Inoshima Y, Fukushi H, Hirai K (1997): Sequence and phylogenetic analysis of highly virulent infectious bursal disease virus. Arch. Virol. 142, 1441-1458. https://doi.org/10.1007/ $\underline{\mathrm{s} 007050050171}$

Yuwen Y, Gao Y, Gao H, Qi X, Li T, Liu W, Wang X (2008): Sequence analysis of the VP2 hypervariable region of eight very virulent infectious bursal disease virus isolates from the northeast of China. Avian Dis. 52, 284-290. https://doi. org/10.1637/8175-111707-Reg.1 